\title{
Design and Study of 7 - Tier Architecture Model for Opening Account in Present Financial System
}

\author{
Vaibhav R. Bhedi \\ Assistant Professor \\ VMV Commerce, JMT Arts and \\ JJP Science College, Nagpur
}

\author{
Ujwal A. Lanjewar \\ Professor \\ VMV Commerce, JMT Arts and \\ JJP Science College, Nagpur
}

\author{
Shrinivas P. Deshpande \\ Associate Professor \\ P.G.D.C.S.T, D.C.P.E, H.V.P.M \\ Amravati.
}

\begin{abstract}
Today core banking has become the major part of financial system. Presently, to fulfill the basic financial needs, the customer open different account numbers in different banks, financial institutions, Provident funds, Mutual funds, Insurances, etc. for various transactions. The major drawback of this system is that, there is no unique identification code of a customer to maintain various transactions and different accounts detail in different branches of different banks and financial institutions.

In this paper, we have tried to focus to remove the above drawback by introducing the 7-tier architecture to maintain the Bank unique identification code (BUID code). Here the 7tier architecture model is designed with the seven layers with the use of biometric tools and the data of customers are stored in Data Warehouse through data mart. This model will help in decision making process by using OLAP and OLTP tools. The main advantage of this model is that the 7-tier architecture model with BUID can easily blend with current finance system. Thus the 7-tier architectural model can become a robust to perform a role to enhance the present account opening process in financial system.
\end{abstract}

\section{Keywords}

7-tier Architecture, Bank Unique Identification (BUID), OLTP, OLAP, Bank Account Number (BAN).

\section{INTRODUCTION}

Now a day's, most banks use core banking applications to support their operations where CORE stands for "centralized online real-time exchange". This basically means that the entire bank's branches access applications from centralized data centers. This means that the deposits made are reflected immediately on the bank's servers and the customer can withdraw the deposited money from any of the bank's branches throughout the world. These applications now also have the capability to address the needs of corporate customers, providing a comprehensive banking solution but still core banking solution have some limitation that the system cannot identify the customer accounts transactions of different bank's branches. The 7-tier architecture model is designed for account opening process using seven layers with biometric tools and the data of customer is stored in Data Warehouse through data mart with BUID. Banks will make available all transactions across multiple channels like ATMs, Internet Banking, Insurances, and etc. using customer BUID. All these facilities have made available to customers using the concept of Data Warehouse where it is a repository of subjectively selected and adapted operational data, which can successfully answer any ad-hoc, complex, statistical or analytical queries. It is situated at the centre of a decision support system of an organization and contains integrated historical data, both summarized and detailed information.

Here, we have included the bank unique identification code of customer to enhance the current Core financial System using 7-tier architectural model and the core system has radically changed the way in which financial system functions. The greatest advantage of having a Core Bank System is that new features and functionalities can be easily added to the proposed system. Using BUID card of proposed system, the customers can manages his financial needs and transactions. The government authorities like Income Tax department, Financial Industry Regulatory Authority, Financial Services Authority, Reserve Bank of India (RBI), Securities and Exchange Board of India (SEBI), Forward Markets Commission (India) (FMC), Insurance Regulatory and Development Authority (IRDA), etc can easily centralized managed and overall control on all financial system through maintaining data warehouse of either individual or a group.

Electronic funds transfer between banks, online trading in the stock markets etc. can be done using BUID, which were unheard in present era of Core Banking System. Any financial organization who wants to interact with customers and share information within the organization from top to bottom can manage through data warehouse.

\section{CURRENT CORE BANKING SYSTEM}

Financial sector in general and banking industry in particular have under gone transformation due to induction of Information Technology (IT). Financial systems have been in the fore front in use of technology. Core banking solutions is new jargon frequently used in banking circles. The advancement in technology, especially Internet and information technology has led to new ways of doing business in banking. These technologies have cut down time, working simultaneously on different issues and increasing efficiency. The platform where communication technology and information technology are merged to suit core needs of banking is known as core banking solutions. Here, computer software is developed to perform core operations of banking like recording of transactions, passbook 


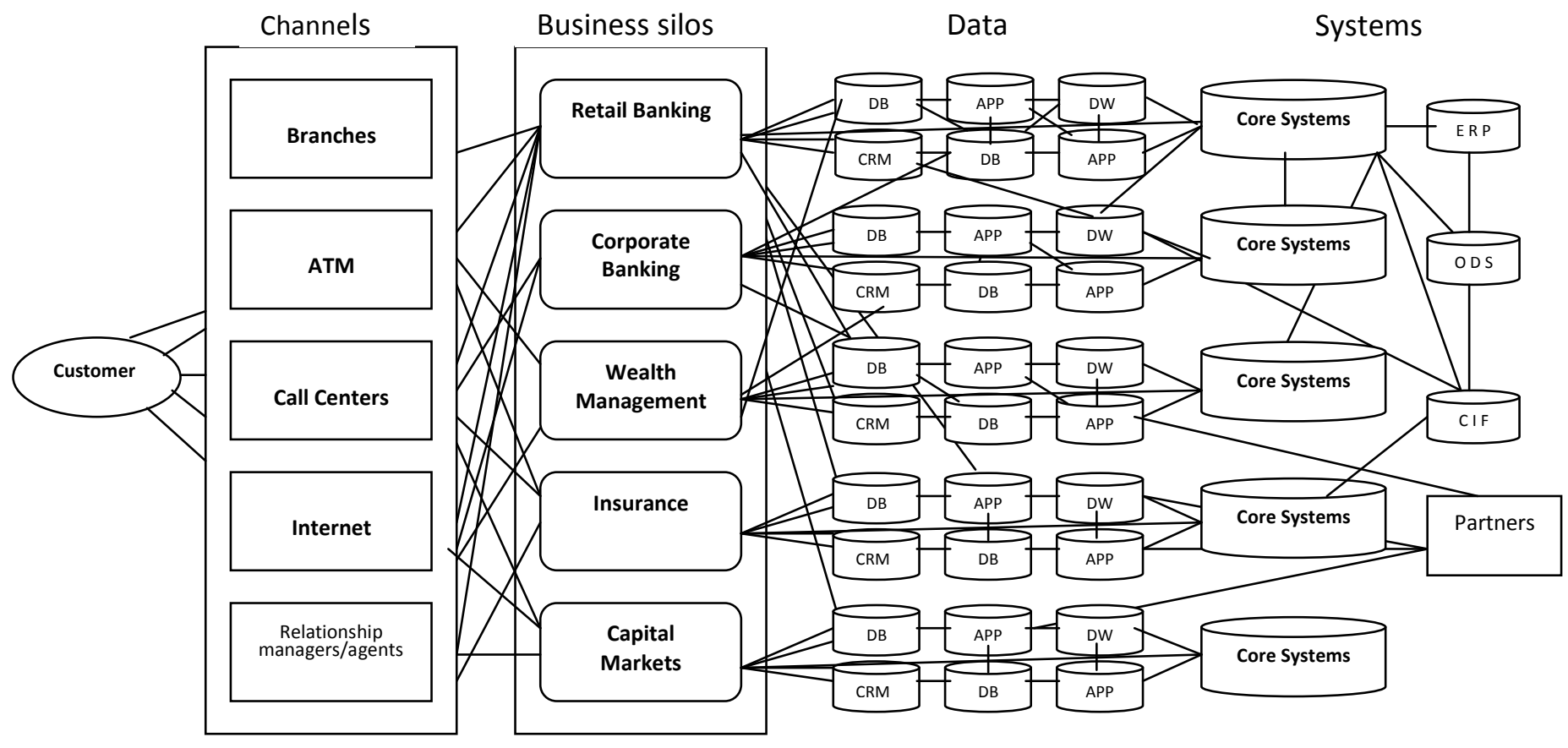

Figure - 1 Current core banking system

maintenance, and interest calculations on loans and deposits, customer records, balance of payments and withdrawal. This software is installed at different branches of bank and then interconnected by means of communication lines like telephones, satellite, internet etc and stored huge volume of data repository in data warehouse. The advantage, a customer can operate on his account from any branch of the bank and if the bank owns Internet Banking or ATM facilities, then the customer can operate on his account from virtually anywhere. It allows the user (customers) to operate accounts from any branch if it has installed core banking solutions.

Core banking has emerged as the most used technology platform amongst banks and in building their technology infrastructure, banks have made huge investments. While this has contributed to growth of business, the return on investment is yet to be realized. As core banking technology is versatile, banks need to move up in the technology value chain and offer value-added services. While development of alternative channels, banks need to guard against depersonalization of service and ensure that they provide consistent banking experience to customers irrespective of the channel used. Though technology would help in building large data repository which could be used for cross-selling purposes, banking continues to remain essentially a service business where customers prefer to feel the personal touch.

It is utmost important for organizations to switch over at earliest on Core banking platform. Implementation of the Core Banking solutions paves the way for Introduction of the electronic funds transfer mechanism in a secure way. Increased regulatory requirements have put pressure on banks. To sustain growth under the circumstances with continued regulatory requirements, it is essential for banks to have the right Core Banking System in place.

\section{FLAWS IN PRESENT ACCOUNT OPENING SYSTEM:}

In present account opening scenario the customer's first real contact with financial system to request to open the account and then the customer directly deals with the initial request step of account opening process by filling the new account opening form. The customer's application form follows the account opening process after completing the initial request step at customer level. Thus customer will get new account number within few days and the entry will be stored in retail account system i.e. the final step of account opening process. Further customer will receive checks, cards etc from the bank.

\subsection{In Above Process There Are Various Flaws in Present Account Opening System, These Are -}

1. In present system, while opening a new account, no records are verified, that whether the customer have any previous accounts in the same branch/bank.

2. The present system is account centric but not customers' transaction centric.

3. Here, it doesn't give any details about the customer in sense of $f$, how many accounts are there in different banks in different locations and its historical data.

4. Thus in present system, it doesn't provide the bank universal unique identification code.

5. In current core system the financial system cannot identify the customer transaction of different accounts at one place.

6. The current system cannot investigate turnover of money from different account of same customer in self system. 


\section{7-TIER ARCHITECTURAL MODEL}

The 7-tier architectural model has become a robust to perform a role to enhance the present account opening process in financial core system. The 7-tier architectural model has seven steps and different process to complete the task. This model will help to control and monitor the Income details, Transaction details and other details of the customers. As we are maintaining Data Warehouse, the data will be stored in a centralized form and can maintain historical data. Due to Data Warehouse, The Online transaction processing (OLTP) and Online Analytical Processing (OLAP) can be used for efficient decision making process. The model will overcome all the drawbacks and will provide the complete solution over the present system.

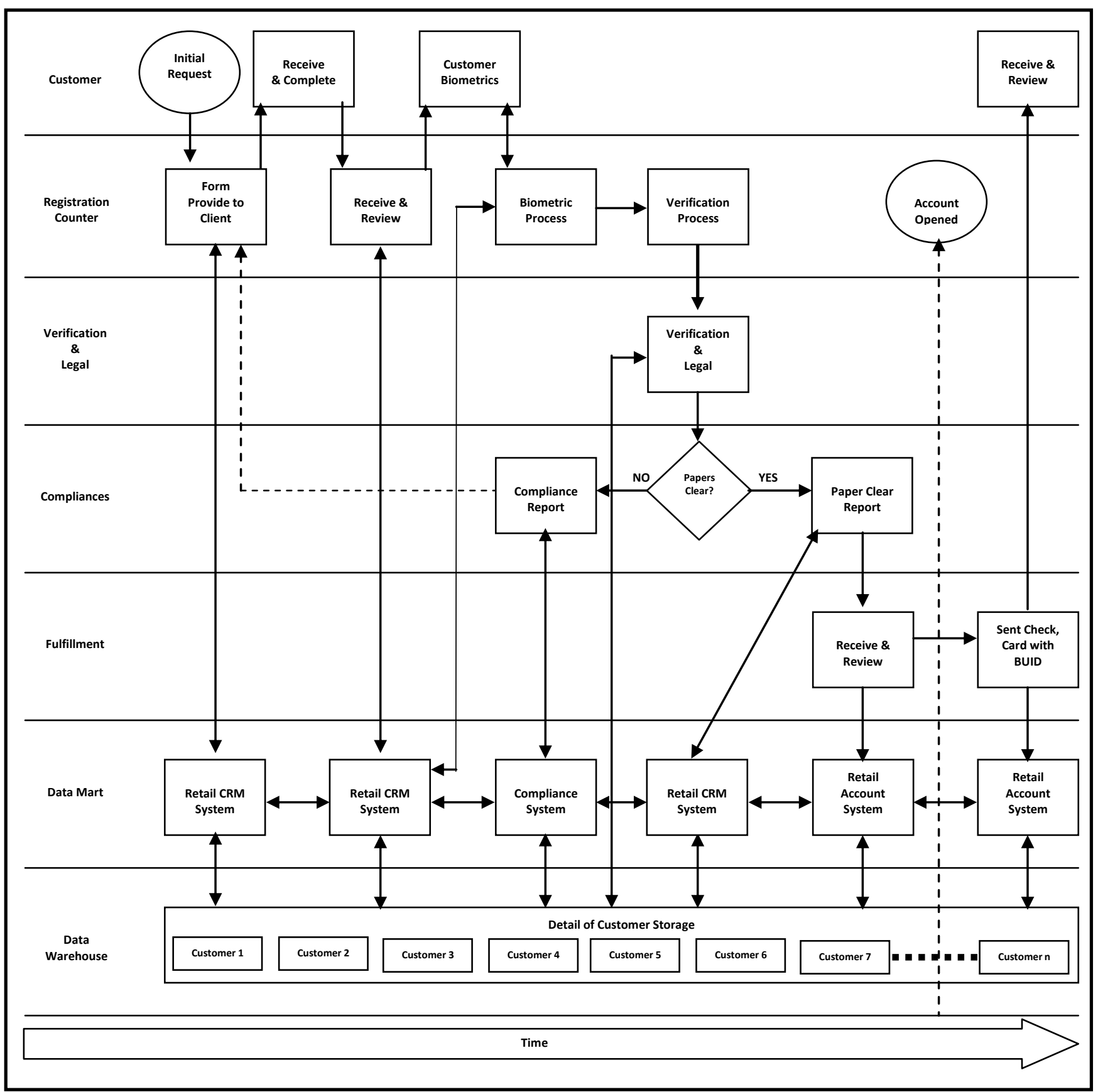

Figure - 2: 7-Tier Architectural Model 


\subsection{Model Description:}

The model has seven layers, these are customer, registration counter, verification and legal, compliances, fulfillment, data mart and data warehouse, defined in well manner and process pursues exactly each and every one steps.

LAYER - 1. Customer: It is extremely initial step of 7-tier architectural model in which customer's first real contact with core financial system for new account opening intention. Customers request to registration counter for account opening form. Then customers submit form to registration counter and then office request customer to provide all detail of biometric.

LAYER - 2. Registration counter: It is second step of model. Customers request to registration counter for account opening form and enquiry. Here the filled form will be received from customer and will further proceed for biometric information and verification of customer. The received and reviewed details will be stored in retail CRM system of data mart. Then the registration counter will receive information of requested new account within few days.

LAYER - 3. Verification and legal: This is the $3^{\text {rd }}$ tier of architectural model. Here, if the customer is opening his account for the first time in his life then the record will be verified and legally checked then the record will be send to next layer without any discrepancies for getting BUID code. And if, the customer is already having his BUID code, then the stored record will be verified with the application form. Suppose the customer is trying to hide his BUID code, then this layer will checked his previous track record by using biometric details. Thus whatever verification and legal reports comes from this layer will be processed to the next layer.

\subsection{Steps for Opening New Account for Customer According To 7-Tier Architecture:}

Step: 1. Customer initially request for new "Account Opening Form (AOF)" to "Registration Counter" for opening new account in any financial system.

Step: 2. After receiving "Account Opening Form (AOF)" the Customer will fill the form.

Step: 3. The Filled form will be submitted by the customer to the registration counter.

Step: 4. After submitting form, the office will ask his biometric detail. This detail will be attached with his form for further process.

Step: 5. If any compliance found in customer's documents, then the compliance report will be given to the customer through registration counter. If the customer is opening his account for first time in his life, then he/she will receive BUID code, BAN, Cards, Books and etc. And if he/she is already having BUID code then only BAN, Card and books will be received.

\subsection{Steps for Opening New Account for Financial System According To 7-Tier Architecture:}

Step: 1. Financial system's registration counter will receive customer request to open a new account.
LAYER - 4. Compliances: If the system won't satisfy with customer document and biometric cross checking process, then the detailed report, which is received from the verification and legal layer will generate compliance report, which will sent to customer, else the request will pass to next step i.e. fulfillment step of 7 - tier architectural model. The compliance step will be stored the compliance report and document detail in data mart of compliance system and retail CRM system respectively.

LAYER - 5. Fulfillment: The application form received without any compliance from the above layer will be fulfilled in this layer by generating Bank Account number (BAN), Cards, Books, etc. If the customer opening his account for first time then the BUID will generate. This BUID will help to observe and store all the transactions done by him from any account. The data generated in this layer will be stored in retail account system of data mart.

LAYER - 6. Data Mart: The Data mart layer will be used by the particular financial system to store the data in retail CRM system, compliances system and retail account system which belongs to registration counter, compliances and fulfillment layer respectively of a particular customer.

LAYER - 7. Data warehouse: This is the last layer of 7-tier Architecture, where each and every details of the customer with every transaction will be stored in data warehouse, which will be maintained by the highest authority of the Government for monitoring the lapses and the defaulters. This layer will store the Historical data and will fulfill any ad hoc, complex, statistical or analytical queries. This layer will be situated at the centre of a decision support system of an organization and contains integrated historical data, both summarized and detailed information.

Step: 2. "Registration Counter" of financial system will provide "Account Opening Form (AOF)" to customer and this detail will be stored in data mart.

Step: 3. 'Registration Counter" will receive filled form by customer.

Step: 4. Office of Financial system will take biometric detail of customer and the detailed information will be stored in retail CRM system. Further the detailed will be passed for verification and legal process.

Step: 5. Here the customer biometric details and documents are verified and legally checked by the office bearer.

Step: 6. The verified documents without any compliance will be sent for next process otherwise, the detailed compliance report will be sent to the customer through "Registration Counter".

Step: 7. Here the customer will be fulfilled by receiving BUID code, BAN number, Cards, Books, etc. Fulfillment step will generate BUID of customer (if not found) and stores data in retail account system. Eventually registration counter will get account opened information and customer will also get checks, cards etc with BUID. 


\section{ADVANTAGES OF BUID USING 7- TIER ARCHITECTURE MODEL}

Following are the advantages of BUID and 7-tier architecture model -

1. New model and BUID code can easily blend with present system, so that the present system can be easily changed into new one.

2. The concept of BUID will help to maintain and monitor the complete transactions of a customer accounts (individual/group/society).

3. The 7 -tier architecture will maintain transparence in account opening system and its transactions.

4. The government can monitor and can easily make decisions regarding financial crises.

5. The Income Tax department need not worry to maintain and control individual details and transactions of customer accounts for Income Tax purpose.

6. The BUID card will be better alternative than the PAN card, since the BUID card maintains biometric detail and his income details.

7. Under this model, all financial sectors, including Government, Private, Public will work under one roof.

8. The Financial system can easily detect the defaulter and can take suitable action.

9. As we maintaining Data Warehouse, The Online transaction processing (OLTP) and Online Analytical Processing (OLAP) can be used for efficient decision making process.

As such, there are many advantages after implementing the 7tier architecture model. Here we have explored only architecture for opening an account number. In our detailed study there are many aspects regarding security, transactions, implementation and software, which will highlight many benefits about the complete system.

\section{CONCLUSION}

The paper is focused on 7-tier architecture model and benefits of BUID code. The seven layers of architecture model shows how transparency can be maintained while generating account number and BUID code. We have made an effort to focus to remove the drawbacks by launching the concept of Bank unique identification code (BUID code). This model will help in decision making process by using OLAP and OLTP tools. The main advantage of this model is that the 7-tier architecture model with BUID can easily blend with current finance system. The 7-tier architectural model has become a robust to perform a role to enhance the present account opening process in financial core system by using BUID.

\section{REFERENCES}

[1] Finacus Solution Pvt. Ltd. Finacus powered by innovation. "FINcore core banking system". Online Available: http://www.finacus.co.in/fincore.html

[2] Scott Simmons, "Modernizing banking core systems" online available: http://www.ibm.com/developerworks/websphere/techjou rnal/0809_col_simmons/0809_col_simmons.html

[3] IBM Global Business Services. "IBM Institute for business value". Online available: http://www05.ibm.com/de/financialservices/pdf/ibv_soa_banking.pd

[4] M/S S. Sathnanakrishanan, 2005. Information System for Banks, 2005, M/S/, Taxman publication, Pvt. Ltd. 